ANUARIO DE ESTUdios MEDIEVALES

48/1, enero-junio de 2018, pp. 181-211

ISSN 0066-5061

https://doi.org/10.3989/aem.2018.48.1.06

\title{
TODOS LOS CAMINOS CONFLUYEN EN BURGOS. CENTRALIDAD Y JERARQUIZACIÓN URBANAS EN LA CASTILLA BAJOMEDIEVAL*
}

\section{ALL ROADS LEAD TO BURGOS. CENTRALITY AND URBAN HIERARCHY IN LATE MEDIEVAL CASTILE}

JAVIER SEBASTIÁN MORENO

Universidad Autónoma de Madrid https://orcid.org/0000-0002-2712-798X. YOLANDA GUERRERO NAVARRETE Universidad Autónoma de Madrid http://orcid.org/ 0000-0003-1766-7656

Resumen: El estudio de los espacios dominados por las ciudades medievales ha sido, desde la década de los ochenta, uno de los temas vertebradores de la historia urbana castellana. Sin romper con esta tradición, en este artículo se va aplicar un nuevo modelo con el que se va a intentar profundizar en los límites que hasta este momento han sido considerados como eminentemente urbanos: un recinto amurallado rodeado por una jurisdicción. Para lograr este fin se aplicarán sobre la ciudad de Burgos conceptos como el de capital regional o región, demostrando que toda gran ciudad medieval, como en la actualidad, ejercía una influencia más allá de las tierras que pertenecían a sus propios dominios. Palabras clave: Burgos; capital regional; región urbana; sistema regional urbano; centralidad; jerarquía urbana.

Abstract: The study of the spaces dominated by medieval cities has been one of the core themes of Castilian urban history since the 1980s. Without breaking with this tradition, in this article we will apply a new model with which an attempt will be made to go beyond the limits that until now have been considered as eminently urban: a walled enclosure surrounded by its area of jurisdiction. In order to achieve this purpose, concepts such as that of regional capital or region will be applied to the city of Burgos, demonstrating that every large medieval city, as happens nowadays, exerted an influence beyond the lands that belonged to its own domains.

Keywords: Burgos; regional capital; urban region; urban regional system; centrality; urban hierarchy.

\section{SUMARIO}

1. Conceptos básicos.- 2. Todos los caminos confluyen en Burgos: la expresión de la centralidad.- 3. La perspectiva de análisis regional como elemento de modificación y precisión de la realidad socioeconómica urbana: el caso de Burgos.- 4. Centralidad y jerarquización: el estatus político de Burgos en la Baja Edad Media.- 5. Conclusiones.- 6. Bibliografía citada.

\footnotetext{
* El presente trabajo forma parte del proyecto de investigación "Ciudad y nobleza en el tránsito a la modernidad: autoritarismo regio, pactismo y conflictividad política. Castilla, de Isabel I a las Comunidades" (ref. HAR2017-83542-P), Ministerio de Economía, Industria y Competitividad/Agencia Estatal de Investigación/Fondo Europeo de Desarrollo Regional, dirigido por el prof. José Antonio Jara Fuente.

Cómo citar este artículo: Sebastián Moreno, Javier y Guerrero Navarrete, Yolanda (2018), Todos los caminos confluyen en Burgos. Centralidad y jerarquización urbanas en la Castilla bajomedieval, "Anuario de Estudios Medievales" 48/1, pp. 181-211. https://doi.org/10.3989/aem.2018.48.1.06

Copyright: (C) 2018 CSIC. Este es un artículo de acceso abierto distribuido bajo los términos de la licencia de uso y distribución Creative Commons Reconocimiento 4.0 Internacional (CC BY 4.0).
} 


\section{CONCEPTOS BÁSICOS ${ }^{1}$}

El presente estudio pretende utilizar como modelo la ciudad de Burgos en los siglos bajomedievales para trascender lo que durante las décadas de los 80 y 90 fue la definición clásica de espacio urbano: un ámbito formado por la propia ciudad y sus tierras jurisdiccionales (alfoz, tierra, señorío...) $)^{2}$. Para alcanzar este objetivo se utilizarán dos conceptos que pocas veces han sido esgrimidos por la historiografía medieval castellana: el primero de ellos, el de capital regional, y el segundo, inexorablemente unido al anterior, el de región urbana ${ }^{3}$.

Entendemos por "capital regional" cualquier núcleo de población capaz de centralizar un número elevado de las relaciones que conforman el sistema de asentamientos de cualquier entidad política, pretérita o presente 4 . A pesar de que en la Castilla bajomedieval no existió una única capital ${ }^{5}$, si hubo ciertos núcleos de población, entre ellos Burgos, que poseyeron unos niveles de centralidad (económica, administrativa, política, cultural, etc.) verdaderamente reseñables, los cuales conformaron una red urbana multipolar totalmente jerarquizada. A su vez definimos este término, el de centralidad, como el grado de atracción y de irradiación que todo núcleo de población ejerce sobre el resto de asentamientos y sus relaciones. A partir de aquí, podemos deducir que la región urbana -segundo concepto del que partimos en este trabajo- es el área que presenta cierta homogeneidad con relación a una serie de condiciones afines, en este caso, a la esfera general de influencia de una capital regional ${ }^{6}$. Evidentemente, la noción de región ha sido empleada por los historiadores del Medievo en infinidad de ocasiones pero casi siempre utilizando parámetros ajenos al entramado relacional sostenido por un lugar

\footnotetext{
${ }^{1}$ Abreviaturas utilizadas: $\mathrm{ACB}=$ Archivo de la Catedral de Burgos; $\mathrm{AGS}=$ Archivo General de Simancas; $\mathrm{AMB}=$ Archivo Municipal de Burgos; $\mathrm{HI}=$ Sección Histórica; INE = Instituto Nacional de Estadística; LL.AA. = Libros de Actas; REG = Registros; RGS = Registro General del Sello.

${ }^{2}$ Asenjo 2005. El presente trabajo recoge una parte mínima de la tesis de Javier Sebastián Moreno, La ciudad medieval como capital regional: Burgos, siglo XV, leída el 5 de abril de 2017 en la UAM y calificada de Sobresaliente cum laude. Recientemente ha sido publicada con el título La ciudad medieval como capital regional. Burgos en el siglo XV (Sebastián 2017).

${ }^{3}$ Dentro de este tipo de aproximaciones, hay que destacar los trabajos de A. Collantes de Terán sobre Sevilla y las ciudades andaluzas, Collantes 2004, 2009-2010, 2014, y de P. Iradiel sobre la red urbana en su conjunto, Iradiel 2003. Uno de los trabajos de referencia sobre esta temática es el de L. Buchholzer-Rémy en el que se analiza la centralidad de la ciudad de Núremberg, Buchholzer-Rémy 2006. Otro estudio destacado es el de J.A. Galloway sobre las áreas económicas en el mundo urbano medieval, Galloway 2000. En las obras de carácter general sobre la historia urbana medieval se suele también hacer referencia a esta problemática, Dutour 2004.

${ }^{4} \mathrm{El}$ término asentamiento hace referencia a cualquier entidad poblacional, ya sea una pequeña aldea o una gran metrópoli.

${ }^{5}$ Carrasco 2009.

${ }^{6}$ Dickinson 1961, p. 23.
} 
central y un conjunto de elementos de menor jerarquía. Por el contrario, los medievalistas al hablar de región casi siempre han recurrido a los espacios definidos por las administraciones territoriales (merindad, adelantamientos, diócesis, etc.), las jurisdicciones locales (alfoz, tierra, señorío, etc.) y las comarcas con cierta homogeneidad geográfica ${ }^{7}$. Y nunca, o casi nunca, han tenido en cuenta aquellas "fronteras" levantadas por el conjunto de elementos que estaban sumamente interrelacionados y centralizados por una capital regional. Este es precisamente el novedoso punto de vista que determinará todas las conclusiones presentadas en este trabajo.

Por lo general, en toda disciplina científica, cuando hablamos de una serie de elementos interconectados, estamos haciendo referencia a un sistema ${ }^{8}$. En este caso le llamaremos "regional urbano", que no es más que el que está formado por una capital regional, un número más o menos elevado de poblaciones y las relaciones que los unen. Siguiendo la definición general, esto significa: en primer lugar, que hay una capital regional que actúa; en segundo lugar, que hay una situación formada por otros núcleos de población que al recibir la acción del lugar central pueden responder y crear una relación; y, en tercer lugar, que de la suma de todos estos componentes resulta el sistema regional, el cual no equivale a la simple adición mecánica de sus partes. Como es lógico, esta división de la realidad no surge de la nada, sino que es el modelo intermedio entre el sistema de asentamientos, en el que se incluyen todos los núcleos de población, y el sistema urbano, en el que sólo se tienen en cuenta los vínculos entre las principales ciudades de un territorio. Ambos, sobre todo el segundo, desarrollados y demostrados durante décadas por la geografía ${ }^{9}$.

$\mathrm{Al}$ introducir a los asentamientos castellanos bajomedievales dentro de un sistema, el estudio del entramado relacional adquiere un papel protagonista, siendo éste el que permite explicar cómo y por qué actúan las distintas poblaciones según la coyuntura. Tradicionalmente, la geografía ha priorizado siempre el estudio de los vínculos comerciales e industriales mantenidos entre varios elementos de una red. Sin embargo, a pesar de que este enfoque economicista sigue primando, lo cierto es que en el último cuarto del siglo XX algunos de los máximos representantes de esta rama del saber ya señalaron que era necesario profundizar en otros campos ajenos al comercio y a la industria, siendo la cultura, la

\footnotetext{
${ }^{7}$ Muchos son los ejemplos dada la dilatada producción de las investigaciones sobre el mundo urbano medieval. Con respecto al territorio burgalés, el espacio se ha delimitado a través de su merindad, Álvarez 1987, su adelantamiento, Arregui 2000, su obispado, Mansilla 1985 , su alfoz y señorío, Bonachía 1978, 1988; Guerrero 1986a, 1989, y su comarca, Casado 1987.

${ }^{8}$ Bertalanffy 1978 .

${ }^{9}$ Algunas obras de carácter general y de referencia son: Beaujeu-Garnier y Chabot 1970 ; Carter 1974; Johnson 1987; George 1982; Ferrer 1992; Precedo 1998. Como balance general sobre esta temática consultar la obra de Capel 2003.
} 
religión, la administración, la defensa, la política, etc., de igual importancia que los anteriores. Un claro ejemplo de esta vertiente es P. George, que considera que una ciudad también cuida el orden social y político regional, en cuyo caso es sede del poder militar y administrativo; esto por no hablar también de su función de centro difusor de la cultura ${ }^{10}$. Éste es sin duda el modelo de capital regional que consideramos se ajusta mejor a la Edad Media, pues Burgos no sólo era un polo comercial, industrial y financiero, sino que también era un centro que irradiaba su influencia administrativa, cultural, religiosa, etc., a decenas de kilómetros de distancia, superando en todos los casos los límites impuestos por su limitada jurisdicción. Obviamente, esta idea de centralidad, a diferencia de la mayor parte de los trabajos hechos hasta el momento, determina que hay tantas regiones como tipos de relaciones, teniendo que analizar las áreas económicas pero también las administrativas, políticas, militares, culturales, espirituales, etc., para poder entender en su totalidad a una capital regional.

Al mismo tiempo, al hablar de capitalidad se está hablando de jerarquía, de poder y de dominación. Estos atributos dependen de la suma cualitativa de los puntos de referencia de la acción, que en este caso son: el tamaño, la ubicación, la posición física con respecto al resto de elementos y, sobre todo, el estatus ${ }^{11}$. Este último no proviene de la percepción que "uno" tiene de sí mismo, sino que es otorgado por el resto de poblaciones y agentes sociales de la Castilla bajomedieval y está determinado por el conjunto de derechos, honores, privilegios, riqueza, etc., que ensalzan o, por el contrario, degradan a un núcleo frente al resto de actores del sistema social. La suma de estos cuatro referentes de la acción da como resultado la jerarquía, que es en definitiva la posición que el núcleo de población ocupa dentro de la estructura del sistema, determinando por completo, debido a las asimetrías generadas, su forma de actuar y de relacionarse con las demás localidades. Obviamente, cuanta más jerarquía, más centralidad y poder irradia el asentamiento en la red, pudiendo imponer su voluntad a otras poblaciones que no tienen tan desarrollados estos atributos $\mathrm{y}$, al mismo tiempo, generando unas regiones que nada, o poco, tienen que ver con sus jurisdicciones.

Esta percepción de la ciudad como el eje o actor principal de un sistema de relaciones de índole regional proporciona una nueva y más com-

\footnotetext{
${ }^{10}$ George 1982, pp. 210-211.

${ }^{11}$ Algunos historiadores han tenido en cuenta otra serie de atributos, predominando en casi todos ellos el tamaño, Vela 1997; Benito 2000. Otros, sin embargo, han ido más allá y han determinado como puntos clave de la jerarquía: la representación estable en las Cortes, la presencia de los dirigentes concejiles en los entramados cortesanos, la influencia territorial de los miembros de las élites locales, la presencia en la población de la alta nobleza, la zonificación urbanocéntrica, etc., Monsalvo 2000-2002. Aunque en ninguno de ellos se ha puesto de relieve la importancia que tiene, precisamente, la red de vínculos para determinar el rango de cada entidad poblacional.
} 
pleta perspectiva del mundo urbano, de su entramado socio-político y socioeconómico, de su funcionamiento interno y de su papel en el conjunto del reino. Ese es precisamente el objetivo perseguido en el presente trabajo: dotar de esa nueva perspectiva a la ciudad de Burgos en el siglo XV a través de su jerarquía, su centralidad, su poder, sus regiones, etc.

Sin embargo, antes de abordar el corpus principal del presente estudio, nos vemos obligados a realizar una última precisión. La ciudad medieval, y Burgos no es una excepción al respecto, es un espacio compartido por múltiples poderes: municipal, eclesiástico (cabildo y obispado), nobiliar y regio ${ }^{12}$. Cada una de estas instancias de poder genera una centralidad diferente $y$, por consiguiente, áreas diversas. A este respecto, hemos de advertir que vamos a centrarnos en las regiones que se derivan de las relaciones emanadas de la autoridad municipal y que hemos soslayado por entero las propias de la acción de las instituciones eclesiásticas, de la nobleza titulada del entorno y de la monarquía, refiriéndonos únicamente a ellas cuando se trate de acciones o situaciones reforzadoras o generadoras de un estatus específico para la ciudad. Así mismo, hemos de precisar también que hay todo un conjunto de relaciones que creemos parte consustancial del sistema regional generado por Burgos y que deberán quedar al margen de este estudio pues requieren de un análisis propio en profundidad; nos referimos al área de influencia cultural, artística y espiritual-religiosa de la ciudad en la Baja Edad Media.

\section{TODOS LOS CAMINOS CONFLUYEN EN BURGOS:}

\section{LA EXPRESIÓN DE LA CENTRALIDAD}

Constituye un hecho sobradamente conocido que Burgos fue en los siglos XIV y XV uno de los centros con mayor población del norte de Castilla ${ }^{13}$, aunque la mayor concentración de núcleos poblados de gran tamaño se produjo en la parte central de la Submeseta Norte, concretamente a ambas márgenes del río Duero y un poco más al norte en Tierra de Campos, entre los

\footnotetext{
${ }^{12}$ Volviéndonos a centrar sólo en la ciudad de Burgos, hay que destacar los trabajos de Bonachía 1978, 1988 y Guerrero 1986a, 2009-2010, para aproximarse a los poderes municipales. Por su parte, el poder de las instituciones eclesiásticas sobre la urbe ha sido analizado en los trabajos de Serrano 1935 y Casado 1980. Asimismo, la presencia e influencia de la nobleza ha sido puesto de manifiesto a través de la familia de los Velasco, Montero 2012. Por último, el poder de la Corona ha sido analizado desde diferentes perspectivas, por ejemplo a través del nombramiento de corregidores, Guerrero 2000-2002.

${ }^{13}$ Ruiz 1967; Martín 1981; INE 2008. El Mapa 1 ha sido confeccionado gracias a la publicación del Censo de Pecheros de Carlos I de 1528 por parte del Instituto Nacional de Estadística. En algunos casos las cifras han sido modificadas según los trabajos que existen al respecto. El caso más paradigmático el de Valladolid, Álvarez, Carreras 1998.
} 
ríos Pisuerga y Valderaduey. A pesar de esto, Burgos poseía un tamaño que nos permite desde el principio considerar que ocupaba un puesto destacado dentro de la estructura del sistema. Precisamente, la primera de las regiones burgalesas que se puede delimitar es la que surge de este punto de referencia de la acción. Como se puede observar en el mapa, tan sólo Castrojeriz (40 $\mathrm{km})$, Villasandino (40 km), Santa María del Campo (35 km), Lerma (40 km), Covarrubias $(40 \mathrm{~km})$, Belorado $(46 \mathrm{~km})$ y Briviesca $(40 \mathrm{~km})$ tenían los suficientes pecheros como para constar en la cartografía. La disposición de estos elementos es clara, están cercando a la capital regional en todos sus flancos a una distancia muy similar, entre 40 y 50 kilómetros. Una distancia que no es producto del azar y que permite defender la idea de que fue en esta área en donde la capital regional, tras superar la crisis del siglo XIV, absorbió la mayor parte del excedente humano, constituyéndose como el ente centralizador de los flujos migratorios comarcales. Así se entiende que en 1501 la cofradía de herradores de Burgos denunciase que los menestrales venidos a la ciudad, obviamente del mundo rural adyacente, abrían sus tiendas sin saber si eran aptos para ejercer el oficio ${ }^{14}$.

Si su número de habitantes fue ciertamente una de sus fortalezas o atributos más destacados, tampoco es necesario demostrar a estas alturas la excepcional ubicación que la ciudad poseyó en la geo-economía de la Baja Edad Media castellana, pues era uno de los puntos centrales del eje nortesur que vertebraba el comercio internacional de Castilla ${ }^{15}$. Si uno se fija con detenimiento en el mapa 2 se ve claramente como hay dos grandes sectores: uno formado por la maraña de poblaciones que estaban en el interior de la Submeseta Norte y el otro por el conjunto de asentamientos situados en la costa y en la Cordillera Cantábrica. En medio de las dos secciones se encontraba la ciudad de Burgos, como puerta principal capaz de comunicar ambos espacios. Por lo tanto, si se tiene en cuenta que las rutas comerciales internacionales fueron las que marcaron o, por lo menos, influyeron en la distribución de los grandes centros, creemos que no es descabellado pensar que Burgos gozaba de una de las mejores ubicaciones de este escenario ${ }^{16}$. Lo mismo se podría decir de la posición física que ocupaba con respecto al resto de elementos, pues según los repertorios de caminos la urbe contaba con un gran número de entradas/salidas, permitiendo a la entidad mantener unas relaciones muy fluidas y, por lo tanto, centralizar una serie de áreas con una elevada integración.

\footnotetext{
${ }^{14}$ AMB, LL.AA., 1501, f. 52r.

${ }^{15}$ Molénat 1971; Pérez-Bustamante 1981; Casado 1987.

${ }^{16}$ Villuga 1951.
} 


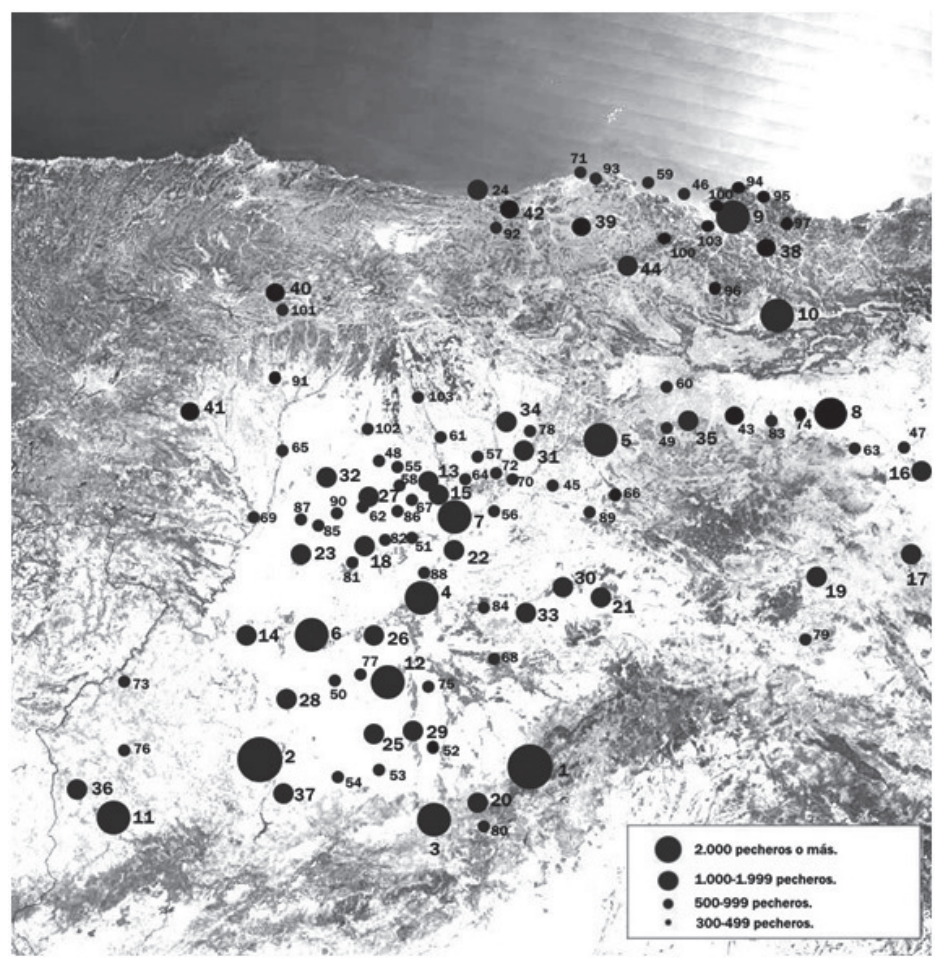

Mapa 1. Red de asentamientos del norte del reino de Castilla a principios del siglo $\mathrm{XVI}^{17}$.

${ }^{17}$ En este trabajo se tienen en cuenta sólo los núcleos de población con más de 299 pecheros: 1. Segovia; 2. Salamanca; 3. Ávila; 4. Valladolid; 5. Burgos; 6. Toro; 7. Palencia; 8. Logroño; 9. Bilbao; 10. Vitoria; 11. Ciudad Rodrigo; 12. Medina del Campo; 13. Paredes de Navas; 14 Zamora; 15 Becerril; 16. Alfaro; 17. Agreda; 18; Medina de Rioseco; 19. Soria; 20. Villacastín; 21. Aranda de Duero; 22. Dueñas; 23. Villalpando; 24. San Vicente de la Barquera; 25. Madrigal de las Altas Torres; 26. Tordesillas; 27. Villalón; 28. Fuentesaúco; 29. Arévalo; 30. Roa; 31. Castrojeriz; 32. Mayorga; 33. Peñafiel; 34. Melgar de Fernamental; 35. Belorado; 36. San Felices de los Gallegos; 37. Alba de Tormes; 38. Durango; 39. Villacarriedo; 40. Cármenes; 41. Astorga; 42. Cabezón de la Sal; 43. Santo Domingo de la Calzada; 44. Espinosa de los Monteros; 45. Santa María del Campo; 46. Castro Urdiales; 47. Calahorra; 48. Villada; 49. Villafranca Montes de Oca; 50. Alaejos; 51. Ampudia; 52. Martín Muñoz; 53. Fontiveros; 54 Peñaranda de Bracamonte; 55. Cisneros; 56. Torquemada; 57. Frómista; 58. Frechilla; 59. Laredo; 60. Briviesca; 61. Carrión de los Condes. 62. Cuenca de Campos; 63. Ocón; 64. Amusco; 65. Valencia de Don Juan; 66. Covarrubias; 67. Fuentes de Nava; 68. Cuéllar; 69. Benavente; 70. San Cebrián de Buena Madre; 71. Santander; 72. Astudillo; 73. Fermoselle; 74. Navarrete; 75. Olmedo; 76. Vitigudino; 77. Nava del Rey; 78. Villasandino; 79. Almazán; 80. Las Navas del Marqués; 81. Villabragima; 82. Palacios de Campos; 83. Nájera; 84. Tudela de Duero; 85. Castroverde de Campos; 86. Castromocho; 87. Villanueva del Campo; 88. Cigales; 89. Lerma; 90. Aguilar de Campos; 91. León; 92. Cabuérniga; 93. Marina de Cudeyo; 94. Bermeo; 95. Lequeitio; 96. Orduña; 97. Marquina; 98. Erandio; 99. Baracaldo; 100. Carranza; 101. Vegacervera; 102. Sahagún; 103. Saldaña. 


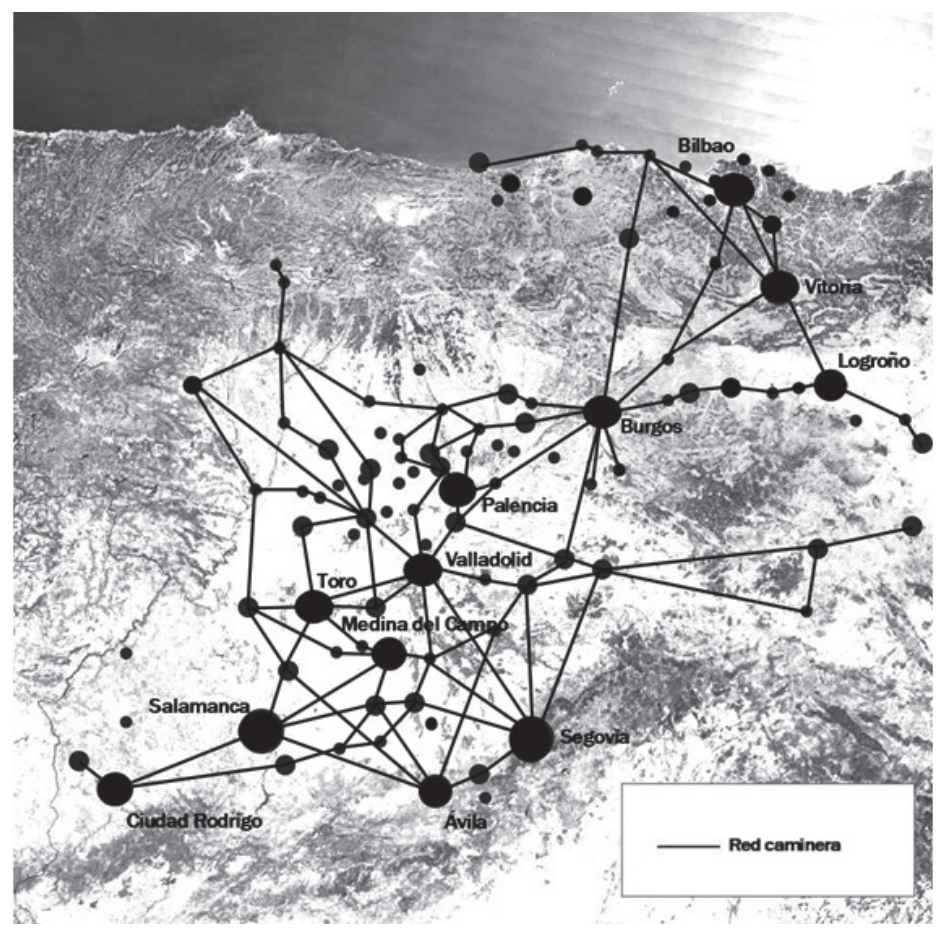

Mapa 2. La red caminera de la escena delimitada.

Como es obvio, el hecho evidente de que "todos los caminos confluyen y fluyen en y desde Burgos" en la parte noreste de Castilla era a la vez consecuencia y causa de la centralidad económica, política, administrativa, etc., que ostentaba la capital regional en el seno de una red de asentamientos perfectamente conectada y estructurada en esta zona. Los ejemplos que mejor demuestran esta realidad son las alegaciones que algunos núcleos de población presentaron para evitar el repartimiento con el que se pretendía pagar la reconstrucción del puente de Melgar de Fernamental a finales del siglo XV ${ }^{18}$. En casi todos los casos las autoridades de los distintos municipios fundamentaron que no utilizaban el paso para acceder a Burgos, afirmando indirectamente que la capital regional del Arlanzón era uno de los centros que ordenaba la red caminera del noreste de Castilla. Así, el 13 de octubre de 1495, los concejos de Piña, Ribas y Amusco rebatían el repartimiento afirmando que el puente se encontraba muy lejos de ellas y que no tenían

\footnotetext{
${ }^{18}$ AGS, RGS, noviembre de 1495, f. 42; AGS, RGS, octubre de 1495, f. 239; AGS, RGS, octubre de 1495, f. 279.
} 
ningund trato de pan e vino o otras mercaderías con la çibdad de Burgos por la mucha distancia de tierra que ay de las dichas villas a la dicha çibdad, (...) e quando las dichas villas e algunas dellas tovieran alguna contrataçión con la dicha çibdad de Burgos de pan o vino o otras cosas que cada una de las dichas villas tienen puentes por donde pasar ${ }^{19}$.

Estos ejemplos muestran a la perfección que el proyecto viario que se desarrolló a finales del siglo XV y principios del XVI estaba basado en la reparación y creación de un sistema de comunicaciones vertebrado en torno a ciudades como Burgos, es decir, en torno a capitales regionales con altas jerarquías.

\section{LA PERSPECTIVA DE ANÁLISIS REGIONAL COMO ELEMENTO DE MODIFICACIÓN Y PRECISIÓN} DE LA REALIDAD SOCIOECONÓMICA URBANA: EL CASO DE BURGOS

Esta situación geoestratégica hizo de Burgos, como se ha dicho hasta la saciedad, una ciudad esencialmente comercial, no sólo en cuanto a las redes internacionales se refiere, sino también con respecto a los circuitos regionales e interregionales ${ }^{20}$. Si a este punto de referencia de la acción le sumamos su tamaño, su elevado estatus económico (privilegios comerciales, mercado franco, ceca, Universidad de Mercaderes, etc.) y la "confianza financiera" que de ello se derivaba, el resultado es una jerarquía de primerísimo nivel que posicionaba a la ciudad como una de las plazas de referencia del noreste de Castilla. Así se entiende que en 1463 la capital regional del Arlanzón fuese capaz de "boicotear" la feria de Medina del Campo cerrando el tráfico de mercadería algunna hasta que Enrique IV mediase y reprendiese al alcaide del castillo por los robos que estaba cometiendo ${ }^{21}$. Esta jerarquía otorgó a la ciudad un grado de centralidad muy elevado que generó unas regiones de una extensión y complejidad extraordinarias.

Lógicamente, resulta imposible describir y analizar todas las áreas suscitadas por las relaciones económicas mantenidas por la ciudad a lo largo del período medieval. Por eso, vamos a centrarnos en una, que creemos muy significativa de lo que queremos demostrar, la región vitivinícola burgalesa. Como veremos, su análisis implica a su vez al área de especialización cerealera o "región-granero" y a la actividad artesana-textil, demostrándose como

${ }^{19}$ AGS, RGS, octubre de 1495, f. 240.

${ }^{20}$ Casado 1997, 2001.

${ }^{21}$ AMB, LL.AA., 1463, f. 98v. 
un hábil modelo de imbricación de las diferentes regiones. A través de ella, igualmente, intentaremos demostrar cómo el análisis del sistema regional de Burgos modifica y amplía las percepciones mantenidas hasta el momento por la historiografía sobre determinadas realidades económicas bajomedievales, al tiempo que permite desentrañar y comprender con mayor precisión y exactitud la política regional llevada a cabo por la élite de gobierno burgalesa en materia de producción, circulación, precios, pesas y medidas, etc.

Es un hecho conocido y comúnmente aceptado que Burgos hubo de crear una región de abastecimiento vitivinícola muy dispersa y alejada del núcleo urbano ${ }^{22}$, que, además, adoptó a lo largo del siglo XV una evolución muy cambiante según se iba produciendo la especialización productiva de algunas comarcas $^{23}$, según se centralizaba el mercado interno en las capitales regionales y según se lograba pacificar el interior del reino. Estos tres factores provocaron que los excedentes circulasen a escala regional e interregional cada vez de forma más fluida, lo que permitió a los núcleos deficitarios reforzar sus relaciones con los centros vinícolas más especializados. Por eso, la documentación demuestra que a principios del siglo XV Burgos consumía mayormente los caldos de su tierra y en menor cantidad los de otros elementos de la red. Por el contrario, a finales de la centuria la presencia de los vinos locales en el mercado era casi inexistente mientras que las referencias a los vendimiados en los centros más especializados era constante: Roa, Gumiel, la comarca de las Nueve Villas, Madrigal, Dueñas, Cigales, Becerril, La Rioja, Toro, etc. Por eso, en las primeras décadas todavía existía una férrea convicción proteccionista mientras que en las últimas eran habituales las licencias para descepar las vides, como la que solicitaba el 23 de enero de 1501 Pedro de Riaño porque, según él, auya mucho tiempo que non se labraba ${ }^{24}$.

Tradicionalmente se ha explicado esta necesidad de generar una red de abastecimiento vitivinícola por la bajísima calidad de los llamados "vinos de la tierra" motivada por las características edafológicas y climáticas de la comarca burgalesa ${ }^{25}$. Sin embargo, desde la perspectiva del análisis regional surge con fuerza otra circunstancia que añade a esa tesis otro factor igual de relevante: nos estamos refiriendo a la especialización cerealera que sufren en el siglo XV las tierras circundantes a Burgos y que obliga a retroceder a un cultivo como la vid, más costoso y menos rentable ${ }^{26}$. Hablar de una espe-

${ }^{22}$ Guerrero 1986a; Casado 1987.

${ }^{23}$ Pascual 1986; Goicolea 1994, 1999, 2007; Ladero 1995, Huezt 2004.

${ }^{24}$ AMB LL.AA., 1501, ff. 22v y 23 r.

${ }^{25}$ Huezt 2004.

${ }^{26}$ Lo mismo ocurre con los pastos, viéndose una transformación similar en la región de abastecimiento cárnica, Bonachía 1992. 
cialización productiva ${ }^{27}$, significa acabar con otro mito de la historiografía económica de Burgos: su condición de región deficitaria de cereal. La famosa frase del no menos ilustre viajero del siglo XV Navagero, hasta el sol se trae a Burgos de otras partes, empieza a perder su fundamento desde una perspectiva regionalista. Durante muchos años, la condición de "ciudad de acarreo", indiscutida por todos los especialistas del Burgos bajomedieval, se ha visto sustentada por el irrisorio tamaño del territorio jurisdiccionalmente (alfoz) dependiente de la ciudad y destinado en origen a su abastecimiento. Hoy sabemos, bajo un enfoque regional, que la capital regional del Arlanzón era capaz de extender sus tentáculos y su poder hasta donde fuera necesario para lograr su pleno abastecimiento, generando así toda una serie de regiones de las que alimentarse y que, como es obvio por las características de la urbe, superaban con creces los límites de su propia jurisdicción.

Según H. Casado, la "región-granero" estaría constituida en el siglo $\mathrm{XV}$ por las tierras situadas a 30 kilómetros en torno a la urbe ${ }^{28}$. Su estudio, basado en las fuentes del cabildo catedralicio, deja meridianamente claro que la capital regional se abastecía del cereal producido en el territorio donde se agrupaban las posesiones de esta institución. Sin embargo, tras la crisis especulativa provocada por la Pragmática dictada por los Reyes Católicos el 23 de diciembre de 1502 se ha podido comprobar que realmente el área cerealera de Burgos estaba constituida por las tierras situadas a 10 leguas, unos 55 kilómetros. Aunque no podamos entrar en detalles, si es necesario adelantar que a todos los efectos la citada pragmática significó para Burgos la pérdida de su capacidad para atraer el excedente de su antigua región frumentaria. Esto introdujo a la entidad en los circuitos de distribución interregionales, mucho más inestables y, sobre todo, perjudiciales para la hacienda municipal, para el consumidor y, lo que es más importante, para sus élites. Por eso, en 1504, ante la incapacidad de la capital regional para abastecerse de su antigua región, el rey Fernando daría la orden de que todo el excedente encontrado a 10 leguas fuese llevado de forma inmediata al mercado central ${ }^{29}$. Dado que este ordenamiento fue asumido con total naturalidad por la élite de gobierno de la urbe,

${ }^{27}$ La especialización ha sido ampliamente documentada para amplia zonas castellanas en el siglo XV. Los ejemplos mejor estudiados son las villas riojanas, en especial Haro, Goicolea 1994, 1999. O algunas localidades de Tierra de Campos como Becerril, Martínez 1985, Martín 1992. Aunque el caso más paradigmático es el de Madrigal de las Altas Torres que suministraba vino blanco a todo el norte de Castilla, incluidos a lugares centrales con una alta producción vinícola como Zamora, Ladero 1995, p. 37.

${ }^{28}$ Casado 1987.

${ }^{29}$ AMB , HI 3020. Asimismo, en 1506, Fernando el Católico mandó que los concejos, villas y lugares de la jurisdicción de Burgos y de 10 leguas en contorno llevasen a la ciudad el pan que tuviesen para venderlo, en AMB, HI 3025. 
por los propietarios del excedente y por los núcleos insertos en esta zona, nuestra opinión es que la distancia marcada se correspondía con el espacio en el que la ciudad había venido ejerciendo su centralidad desde mucho antes.

La política consciente de la capital regional fue, además del crecimiento demográfico o las características del terruño burgalés, la causa principal de esta especialización cerealera. La ciudad de Burgos, valiéndose de su jerarquía, impuso unas directrices productivas en unos núcleos de población que no tenían ningún tipo de vinculación jurisdiccional con ella. La influencia del ente urbano no entendía de estos límites, tan sólo dependía de su poder de irradiación dentro de la red. A cambio de esta dominación, los asentamientos rurales se beneficiaban de los productos artesanales (jubones, platería, joyería, etc.) y de los servicios (educación, notarías, banca, etc.) ofrecidos por el lugar central. De hecho, la ciudad del Arlanzón sostuvo durante todo el siglo XV una región cerealera de redistribución con la que pudo compensar la balanza de importaciones/exportaciones y acceder a los productos de las núcleos más especializados. Como se puede comprobar en 1474, año en que Haro estipulaba que por cuanto los que benían por vino non lo fallaban, que cada uno aya de dar el diesmo de lo que tiene et si burgales lo oviere de llevar que se escriba a la çibdad fagan traer trigo donde non que non se les dará ${ }^{30}$. Aparte de los núcleos que exigían el grano burgalés para llevar a cabo las transacciones, la región redistributiva también abarcaba las comarcas vascas y cántabras, tanto las situadas en las costas como en la propia Cordillera Cantábrica ${ }^{31}$.

Hasta cierto punto es lógico que la ciudad de Burgos lograse imponer su voluntad en su "región-granero" al estar constituida por las tierras más próximas. Sin embargo, se puede comprobar que la capital regional también fue capaz de influir e incluso determinar la producción, la circulación, los precios, los pesos y medidas, etc., en núcleos situados a decenas de kilómetros de distancia. Concretamente, en aquellos que formaban parte de la región vinícola, que constituye un excelente ejemplo de región fuertemente jerarquizada y ordenada por una capital regional, en este caso Burgos, a pesar de su dispersión y complejidad. Como hemos dicho páginas atrás, determinadas medidas orientadas a la protección de la producción local, como son la protección del viñedo burgalés, la veda de las exportaciones y la prohibición de importar vinos foráneos los primeros meses van poco a poco desapareciendo ${ }^{32}$. La razón es obvia, la especialización cerealera y la paulatina desaparición del viñedo hacía inne-

\footnotetext{
${ }^{30}$ Goicolea 1994, p. 114.

${ }^{31}$ Arízaga 1985; Díaz de Durana 1990; Solórzano 2002.

${ }^{32}$ Medidas que tienen los núcleos que se especializan en la producción de vinos de buena calidad. Por ejemplo, Haro, Zamora o Medina del Campo. Pascual 1986; Goicolea 1994, 1999 , 2007; Ladero 1995.
} 
cesaria la aplicación de una política proteccionista sobre los caldos autóctonos. Esto incitó a la capital regional y a su élite a crear una política regional más compleja que la anterior y siempre con miras a consolidar el área vitivinícola de la que dependía el abastecimiento urbano. Objetivo que se logró durante todo el siglo XV gracias en parte a que, a diferencia del grano, este producto era poco susceptible a la especulación por las dificultades que entrañaba su acaparamiento. La construcción de una región económica de estas características requiere de unas políticas y acciones concretas. Vamos a detallarlas a continuación con la intención de constituir con ellas un modelo explicativo que se repite, con variaciones lógicas, en el resto de las regiones económicas burgalesas y que, lamentablemente, la falta de espacio nos impide abordar.

La primera acción destacable debe hacer referencia a la compra y venta regular de los excedentes producidos en otras tierras, generando con estas transacciones una interdependencia mutua pero asimétrica que permitía que Burgos pudiese imponer sus precios, sus medidas, sus cláusulas contractuales, etc., es decir, su poder dentro del sistema. Gracias a su mercado y a la confianza que éste generaba, Burgos tenía un estatus económico de primer orden y, por eso, era visto por los núcleos productores como una plaza irrenunciable. Lo mismo se puede decir de su tamaño, que generaba una de las demandas más grandes de todo el noreste castellano. Por último, como ya ha sido analizado, su posición en la red viaria también era ventajosa, ya que era la "puerta" que unía las tierras deficitarias del norte y las comarcas productoras meseteñas. En definitiva, la capital regional burgalesa reunía todas las condiciones necesarias para ser un mercado ineludible para los productores y comerciantes de este producto. Sin embargo, la distancia y la complejidad de la región obligaban a las partes relacionadas a construir unos vínculos mucho más formales y reglados que en el área cerealera. Objetivo que se logró a través de dos modalidades contractuales. En el primero de los casos, la vinculación surgía cuando Burgos enviaba a sus representantes a comprar los vinos a las localidades excedentarias. El segundo modo, siendo el polo opuesto, aparecía cuando los núcleos productores acudían a la capital regional a ofrecer la nueva añada. Según los datos que se conservan, estas dos situaciones se dieron de forma simultánea, aunque bien es cierto que la segunda modalidad fue la más habitual a partir del reinado de los Reyes Católicos. La propia evolución demuestra que Burgos a finales del siglo XV era ya considerada por los núcleos productores como uno de los mercados vinícolas más importantes del noreste de Castilla. Para que estas dos modalidades tuviesen efectos reales, y ante la complejidad de la región constituida por Burgos, la élite de gobierno decidió aprobar la creación a principios del siglo XV de una cofradía de taberneros que se encargase, casi en régimen de monopolio, del entramado relacional que procuraba el abastecimiento. 


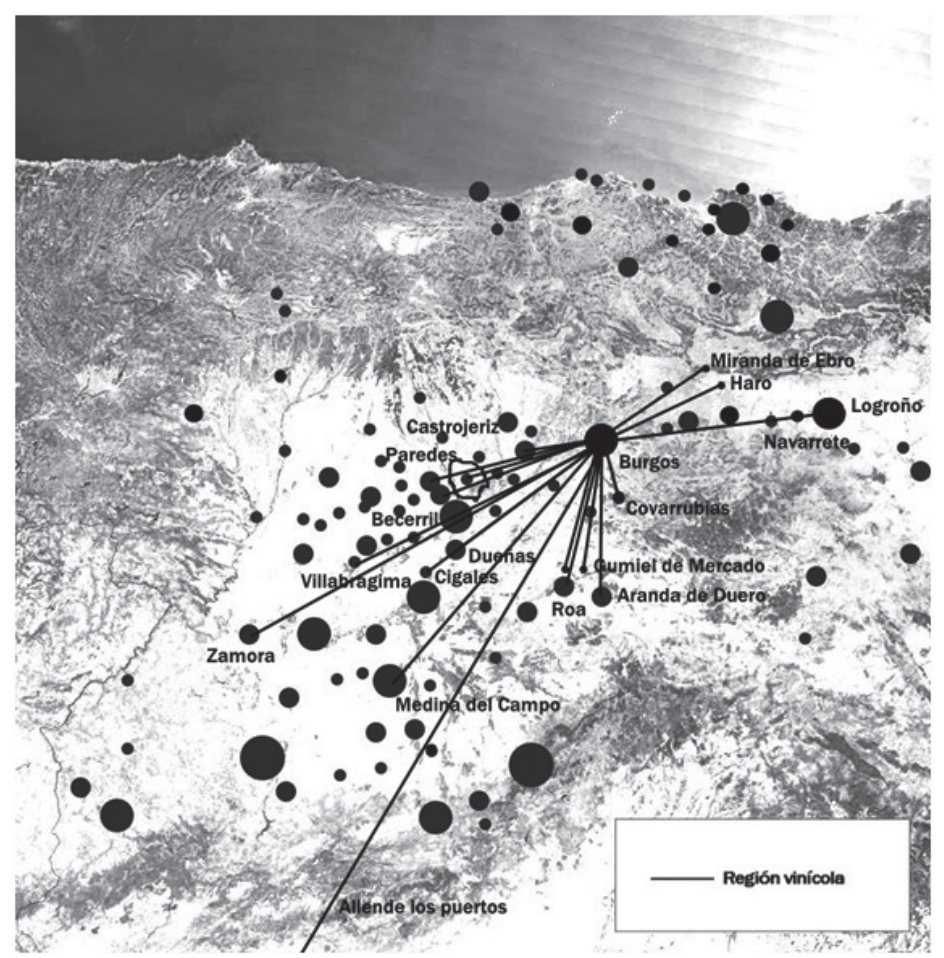

Mapa 3. La región vinícola burgalesa en el reinado de los Reyes Católicos.

Uno de los ejemplos contractuales más arquetípico está fechado en 1458, año en que el regimiento burgalés recibe una carta de la villa de Cigales que dice:

otorgamos e concedemos por esta carta que demos de nuestro poder cumplido segund que mejor e más complidamente que Juan García Mazanero y Alvar Rodríguez, nuestros vecinos, en nuestro nombre puedan vender a los sennores, conçejo, alçaldes de la çibdad de Burgos, Cabeza de Castilla, e a quien ellos mandaran, todo el vino que quisieren e toviesen en nuestro nombre a precios e precios que quisieren e por bien tovieren ${ }^{33}$.

Una vez recibida este tipo de ofertas, el regimiento y los delegados entablaban una negociación que podía desembocar en la compra del vino. En este caso se acordó la saca de 4.000 cántaras (a 13,5 maravedíes la unidad)

${ }^{33}$ AMB, LL.AA., 1458, f. 24r-v. 
entre el 15 de febrero y Pascua de Flores, con la condición añadida de que la villa vendiese a los taberneros de Burgos el celemín de cebada a tres blancas viejas $^{34}$. El modelo es claro: primero, la compraventa de grandes remesas, siempre según las necesidades de la capital regional; segundo, la negociación del precio, favoreciendo siempre al consumidor burgalés; tercero, la posibilidad de incluir otras contraprestaciones para llegar a un acuerdo, en este caso la venta de cebada a buen precio; y por último, la estipulación del tiempo en el que se tenía que sacar el cargamento del elemento excedentario. En otras palabras, en la mayor parte de los casos, la capital regional era capaz de imponer unas condiciones ventajosas. A cambio, los centros productores y los propietarios de los excedentes se aseguraban la venta de la mayor parte de la cosecha en una época en que dar salida a todos los excedentes era prioritario dadas las deficiencias del almacenaje. Además, como es lógico, estos grandes contratos reportaban a los propietarios muchas ganancias en poco tiempo.

Una segunda medida de política urbana vitivinícola tenía como objetivo la consolidación y perfecto funcionamiento de esta red. Para ello la ciudad empleó el sistema de bloqueos y su contrapartida, la concesión de "monopolios parciales". La élite de gobierno confirió a algunas localidades, como medio de control de los flujos excedentarios, un cierto grado de exclusividad. Por ejemplo, en 1436 la capital regional solicitó al rey Juan II que permitiese que durante dos meses sólo pudiesen llegar los caldos de Toro y Madrigal ${ }^{35}$. Por el contrario, igual que podía aplicar estas medidas, también era capaz de crear bloqueos comerciales que presionaban y ponían en un brete a los núcleos productores que los padecían. El objetivo de esta medida no sólo era económico, también estaba muy ligado a las rivalidades políticas, a la fiscalidad, a la seguridad y a la propia supervivencia de la capital regional. Un ejemplo claro está fechado el 9 de abril de 1461, día en que el regimiento prohibía a la cofradía de taberneros ir a por vinos a la villa de Madrigal de la Altas Torres debido a que sus mercaderes se negaban a pagar la sisa y otros impuestos sobre el vino blanco $^{36}$. Esto derivó en una negociación en la que la urbe salió finalmente beneficiada. El análisis de este caso permite extraer conclusiones muy interesantes sobre el veto comercial: en primer lugar, el mercado de la capital era tan importante para los centros productores que a pesar de las fuertes cargas fiscales existentes seguía siendo rentable; en segundo lugar, los centros productores basaban su economía en la exportación, y un vedamiento prolongado podía arruinar a las localidades vinícolas y a los mercaderes vinculados con

${ }^{34}$ AMB, LL.AA., 1458, f. 24r-v.

${ }^{35}$ AMB, LL.AA., 1436, f. 52r.

${ }^{36}$ AMB, LL.AA., 1461, f. 41r. 
este negocio; al mismo tiempo, se puede comprobar en la documentación cómo la élite de gobierno no podía tensar las negociaciones al máximo, a pesar de su posicionamiento en el sistema, ya que conllevaba el desabastecimiento y, por lo tanto, la conflictividad social; en cuarto lugar, los bloqueos también servían para mejorar las relaciones y las condiciones contractuales; en quinto lugar, la mayor parte de las veces los bloqueos eran por motivos políticos, la presión económica a los concejos rivales era y es una de las medidas más eficaces para debilitar a los grupos opositores; por último, los conflictos comerciales dentro de la región de abastecimiento se resolvían, normalmente, con acuerdos que eran beneficiosos para ambas partes, aunque el lugar central solía salir beneficiado por su extensa región, permitiéndole prescindir del vino de algunos elementos sin que su abastecimiento se viese perjudicado.

Lógicamente una tercera acción en materia de política vitivinícola burgalesa, común a toda región económica, fue el éxito en la imposición de precios en el conjunto de la región. El control de los precios fue fundamental para consolidar la centralidad de la urbe sobre su área de abastecimiento vinícola. Con este poder el concejo podía influir de forma determinante sobre la circulación del excedente dentro de esta red tan amplia y dispersa. Por eso, las tasaciones eran hechas siempre por los regidores, alcaldes o jueces de los fieles. Bien es cierto, que este sistema no era tan intransigente, ya que la negociación con los taberneros y con los exportadores estaba en todo momento presente. Así se muestra en 1461, cuando el regimiento envía dos personas a Nueve Villas y a toda la comarca para que trajesen sus caldos poniéndoselo $a$ preçios razonables de manera que ganen ${ }^{37}$. Por supuesto, hay otros factores que influían, y de qué manera, en el valor final de los caldos: la calidad, el tiempo de vino, el recipiente en el que había sido conservado, el precio de salida, las sisas, el lugar de procedencia, la distancia que los mulateros o carreteros tenían que recorrer, etc. Es evidente que cada legua andada aumentaba el precio final del producto, tanto era así, que una bajada de los precios en la cebada, alimento de las bestias, era motivo suficiente para que los consumidores pidiesen un descenso en el importe de los caldos, como así sucedió, por ejemplo, el 19 de abril de 1436, día en que se requirió que baxaren los preçios de los vynos pues la çeuada estaua en preçios baxos ${ }^{38}$. Sin embargo, aparte de las razones que afectaban a cualquier intercambio comercial, existieron otras ajenas a la lógica económica que también influyeron, pues la ciudad durante todo el siglo XV y XVI pujó de forma especial los vinos de ciertas localidades para favorecer a las familias nobiliarias que las detentaban y así conseguir

${ }^{37}$ AMB, LL.AA., 1461, f. 40v.

${ }^{38}$ AMB, LL.AA., 1436, f. 39r. 
a posteriori su apoyo y sus favores. Por ejemplo, el 22 de abril de 1447, el conde de Haro pidió que los vinos de Becerril valiesen un cornado más que los de Cigales y Nueve Villas ${ }^{39}$. Tres años después, la mujer de Pedro Manrique pedía que se pusiese el vino de Hamusco igual que el de Becerril ${ }^{40}$. Petición que fue concedida más tarde, el 22 de agosto, cuando se pujaron los vinos de ambas localidades a 2 maravedíes la azumbre ${ }^{41}$. Por estas fechas los Manrique y los Haro estaba enfrentados y su lucha la llevaban a todos los escenarios posibles, incluido el comercial, teniendo una repercusión en la política de exportación y en los precios de la capital regional.

Aparte de la imposición de los precios dentro del área de abastecimiento gracias a la "tiranía" del mercado burgalés, las fuentes en algunas ocasiones muestran también como las variaciones en las tasaciones eran programadas por la élite del gobierno para favorecer la atracción del excedente de ciertas comarcas y para generar una competencia entre productores dentro de su área de abastecimiento. El ejemplo más paradigmático se produce en el $1462^{42}$. En este año, la villa de Castrojeriz empezó a recaudar un impuesto nuevo a los taberneros burgaleses cada vez que pasaban por sus tierras, según la villa para arreglar las calzadas. De forma inmediata, la ciudad prohibió pasar a los taberneros por Castrojeriz y aumentó el valor de los vinos de Roa y Aranda con el objetivo de llamar su atención y de aumentar la intensidad de la relación. La misma política era llevada a cabo cuando las cosechas no habían sido muy abundantes, así el 20 de octubre de 1496 fablaron los dichos sennores e dixeron sobre la falta de bino que auya en esta çibdad e paresçioles que el vino de Toro se deuya de poner a diez maravedies segund el tiempo e de la carestía del bino e de la çebada ${ }^{43}$. Al mismo tiempo, el lugar central con el control de las tasaciones favorecía expresamente a algunos asentamientos y desfavorecía a otros para crear una región competitiva y en la que Burgos se situase como elemento rector de la misma. La subida en los vinos de una localidad provocaba inmediatamente las quejas de los núcleos que solían ser mejor tasados, pues era sumar un elemento más en las ya de por sí competitivas escalas y tipologías vinícolas. Lo mismo sucedía al revés, es decir, cuando la ciudad tasaba de diferentes maneras dos vinos que tradicionalmente eran iguales. Así es posible entender que cuando el 20 de septiembre de 1429 la ciudad tasó por igual los vinos de Castrojeriz y los de Nueve Villas, inmediatamente, las

\footnotetext{
${ }^{39}$ AMB, LL.AA., 1445-1446-1477, f. 102v.

${ }^{40}$ AMB, LL.AA., 1450, f. 37r.

${ }^{41}$ AMB, LL.AA., 1450, f. 78v.

${ }^{42}$ AMB, LL.AA., 1462, ff. 129v y 130r.

${ }^{43}$ AMB, LL.AA., 1496, f. 150r.
} 
localidades palentinas interpelaron que nunca auia sido as $i^{44}$. Unas quejas que permitieron a Burgos exigir a estas poblaciones que trajesen el mejor vino si querían conservar su posición dentro de la jerarquía de los vinos regionales ${ }^{45}$.

Una última acción de política regional fue la influencia que, bien de manera directa o indirecta, la capital desplegó para que los asentamientos de su red adoptasen sus mismas medidas, aumentando de esta manera la integración de sus áreas de abastecimiento. Así, en 1431, en la villa de Hamusco se ofrecieron a medir con la cántara desta çibdad, y fueron recompensados con una subida de los precios de sus vinos a quantía que valieran que cada un anno en los dichos dies annos conmo los vynos de Becerril ${ }^{46}$. Por lo tanto, el control de los precios también incidió en la homogeneización de las medidas, fundando así un área de abastecimiento en la que la competencia, sobre todo en las décadas de mayor inestabilidad política, era fundamental para el dominio de los flujos que circulaban por los canales de distribución.

En definitiva, como consecuencia de todas estas acciones, Burgos fue capaz de imponer su voluntad, en mayor o menor medida, en la producción y, principalmente, en el tráfico de los vinos cosechados en las tierras de más tradición vinícola del norte de Castilla.

Un último punto a destacar en este somero repaso a la génesis y consolidación de la región vitivinícola del Burgos bajomedieval afecta a la existencia de una región redistributiva del vino que, al igual que en el caso del cereal, abarcaría varias leguas alrededor de la urbe, pues todos los flujos centralizados en Burgos eran irradiados, a su vez, fuera del recinto amurallado. El análisis de estos reflujos arroja luz sobre otra cuestión relevante y demuestra, a su vez, la perfecta imbricación de las diversas áreas en la lógica del sistema regional burgalés, así como también confirma el hecho, ya repetido en muchas ocasiones a lo largo de este trabajo, de cómo la perspectiva regional permite cuestionar antiguos axiomas ampliamente difundidos sobre la estructura productiva de la ciudad. Concretamente nos referimos a la vieja y repetida convicción de la irrelevancia económica de la artesanía burgalesa, especialmente la textil, y que explica difícilmente el importante papel social y económico (demostrado en todas las disputas por la preeminencia de los oficios en las procesiones y festividades urbanas) que sastres, plateros, albañiles y demás oficios artesanales tuvieron en Burgos, así como su mismo número, a todas luces en franca contradicción con dicha aceptada insignificancia.

${ }^{44}$ AMB, LL.AA., 1429-1430, f. 72v.

${ }^{45}$ AMB, LL.AA., 1429-1430, f. 72v.

${ }^{46}$ AMB, LL.AA., 1431-1432-1433, f. 13v. 


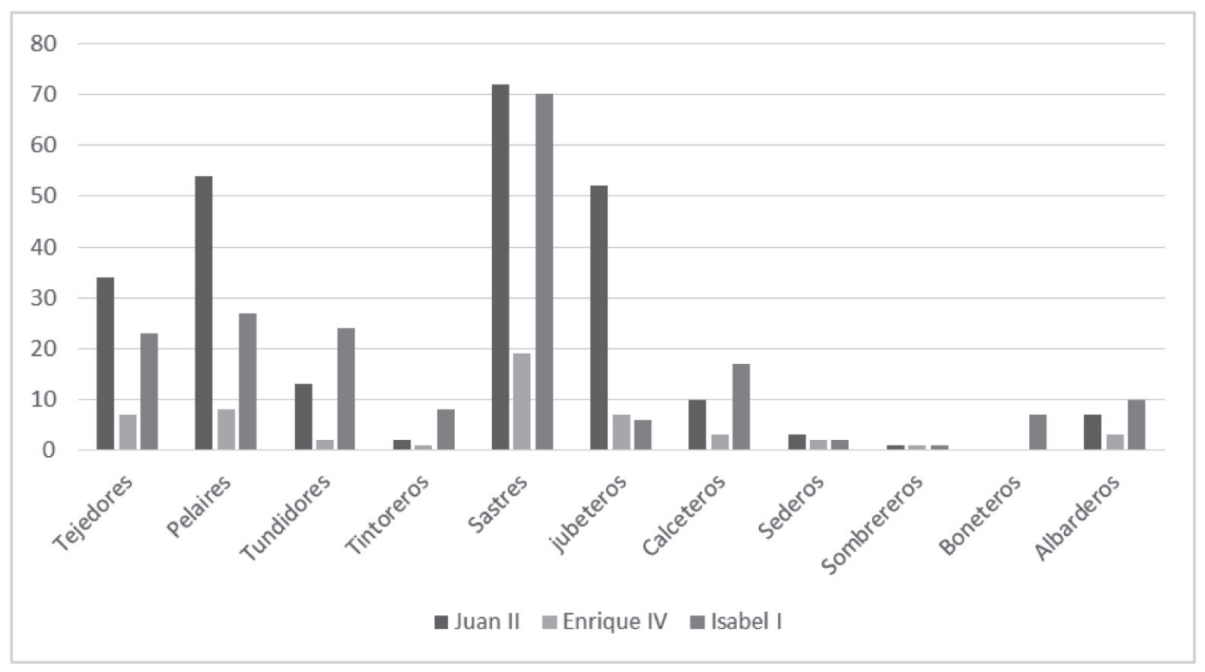

Gráfica 1. Aproximación al número de artesanos vinculados a la artesanía textil ${ }^{47}$.

La elevada cifra de artesanos y su importancia social, sólo adquiere sentido explicada desde una perspectiva regional. En este caso estaríamos hablando de una inversión de los flujos al ser la urbe la que producía e irradiaba los productos; eso sí, en el caso del textil, de baja calidad como impone una demanda eminentemente rural. Por eso, en 1501 las autoridades burgalesas informan a los Reyes Católicos de que en esta dicha çibdad se fasen unos pannos que se llaman guirnaldas e otros que se llaman bervyes de que la gente pobre se sostiene ${ }^{48}$. Desde el punto de vista del flujo de las relaciones y del análisis del sistema regional es factible demostrar que durante la Baja Edad Media el grueso del sector secundario de la comarca burgalesa estuvo plenamente asentado en la capital regional. Este fenómeno es conocido por los economistas como "economía de aglomeración”, que es la tendencia de toda industria a instalarse en donde ya hay empresas del mismo sector para, entre muchas otras ventajas, obtener más fácilmente la materia prima, tener la posibilidad de contratar mano de obra ya formada y poder aprovecharse de un entramado subsidiario y de unas infraestructuras ya levantadas. Es por ello que en el medio rural más cercano a la ciudad de Burgos no hubo un desarrollo artesanal significativo, y el poco que hubo, en todo momento, estuvo

\footnotetext{
${ }^{47}$ Sebastián 2017, p. 227. La gráfica ha sido confeccionada con la documentación atesorada en el Archivo de la Catedral de Burgos, concretamente en Registros, Volúmenes y Libros.

${ }^{48}$ AGS, RGS, febrero de 1501,f. 157.
} 
sometido a la atenta mirada de la ciudad, desde donde se monopolizaron las fases más importantes de la fabricación y, sobre todo, los capitales que las pusieron en marcha ${ }^{49}$. Sin embargo, este contexto ha sido pocas veces puesto de relieve $\mathrm{e}^{50}$. Los medievalistas, extasiados e hipnotizados por "los grandes hombres de negocios" nunca han apreciado como se merece la capacidad artesanal que poseía la ciudad. De hecho, la presencia del capital mercantil es lo que algunos han considerado como la causa fundamental de que Burgos fuese una ciudad eminentemente de acarreo, volcada única y exclusivamente en el comercio ${ }^{51}$. No obstante, la lectura detallada de las fuentes municipales y eclesiásticas arroja de forma continuada noticias y referencias a la producción fabril y a sus protagonistas, dando a entender todo lo contrario de lo que hasta este momento se había asegurado. Por lo tanto, uno de los roles principales que Burgos asumió fue el artesanal. Mientras la entidad se alimentaba de sus regiones de abastecimiento, ella dedicaba sus esfuerzos a proporcionar a los asentamientos rurales de sus alrededores productos manufacturados de distinta calidad. Por eso creemos que es justo pensar que Burgos alcanzó en el siglo $\mathrm{XV}$ un nivel de desarrollo artesanal similar al del resto de centros que tenían sus mismos atributos ${ }^{52}$.

\section{CENTRALIDAD Y JERARQUIZACIÓN: \\ El estatus POlítico DE BURgos EN LA BAJA EDAd MEdia}

A pesar de que las regiones económicas son, sin duda, el elemento del sistema más fácil de reconstruir debido a su importancia y al cariz de la documentación conservada, debemos recordar que la centralidad no hace referencia, ni tampoco lo hizo al final de la Edad Media, a aspectos exclusivamente económicos. En definitiva, Burgos no sólo era un centro económico de primer nivel también era un sujeto político capaz de actuar dentro y fuera del sistema de asentamientos. Como bien afirma J. $\mathbf{M}^{\mathrm{a}}$. Monsalvo, las ciudades, en concreto sus élites de gobierno, no dejan de ser una fuerza que compite con los señores y que provoca tensiones dialécticas en el seno del estado central, produciendo flujos decisionales ${ }^{53}$. Esta perspectiva redunda en la idea de que el mundo bipolar nobleza-monarquía no es válido para entender las relaciones de poder que se constituyeron en el siglo $\mathrm{XV}$, siendo realmente la urdimbre

\footnotetext{
${ }^{49}$ Casado 1987.

${ }^{50}$ Bonachía 1984.

${ }^{51}$ Casado 1987.

${ }^{52}$ Iradiel 1974; Asenjo 1986; González 2009.

${ }^{53}$ Monsalvo 1986, p. 153.
} 
relacional sostenida por el rey, la nobleza y las principales capitales regionales la que finalmente dio lugar a la estructura denominada como Estado Moderno ${ }^{54}$. Una urdimbre que en los momentos de mayor inestabilidad política atendía a la fórmula relacional: "monarquía-colectivo de capitales regionales/ colectivo de capitales regionales-colectivo de nobles/colectivo de nobles".

La construcción de Burgos como agente político y la consolidación de su elevado status fue un proceso gradual durante todo el período medieval que se materializó y reforzó a través del incremento de su nobleza, de su señorío, de su prelación en las Cortes, de su prestancia y monumentalidad, de los linajes que vivían en ella, etc. ${ }^{55}$. Todos estos aspectos son bien conocidos y no insistiremos sobre ellos. Sólo un pequeño ejemplo del reconocimiento hacia Burgos por parte del resto de los actores políticos de la Castilla bajomedieval. En 1476, ante la pérdida inminente del castillo por parte de los partidarios de la princesa Juana, Álvaro de Stuñiga pidió encarecidamente ayuda al rey de Portugal porque sólo poseyendo la ciudad se pueden con buena confiança llamar reyes dél (Castilla), porque es Cabeza de Castilla e Cámara de los reyes ${ }^{56}$, siendo imposible gobernar el reino sin que en la diadema del Monarca legítimo estuviese el florón de aquella ciudad, Cabeza de Castilla, y no dudar nadie de que su posesión ó de su pérdida dependía la gloria futura ó el futuro oprobio $^{57}$.

Esta centralidad "institucional" de la ciudad, derivada de su condición en el sistema-reino, se tradujo en todo un conjunto de acciones políticas dentro de la red de asentamientos que generaron a su vez lo que podríamos designar como "región política". Nos centraremos fundamentalmente en dos, que nos parecen especialmente significativas, aunque con diferentes proyecciones políticas, más "nacional" la primera, más "regional" la segunda.

En primer lugar, la preeminencia política de Burgos se refleja en las ordenanzas que en 1446 la élite de gobierno creó sobre el número de procuradores que debían ser enviados a Cortes ${ }^{58}$. Mientras Juan II quería que sólo fuese un procurador al encuentro, Burgos defendió que se mantuviesen los dos que desde hacía décadas se estaban enviando, dejando bien claro que a pesar del incremento del poder real las grandes ciudades todavía tenían cierto control sobre esta institución. Para hacer un frente común la urbe creó unas ordenanzas que envió a León, Zamora, Valladolid, Salamanca, Soria, Ávila, Toro y Segovia para que las leyesen y defendiesen frente la arbitrariedad del

\footnotetext{
${ }^{54}$ Ladero 1987.

${ }^{55}$ Bonachía 1996.

${ }^{56}$ Pulgar 2008, p. 155.

${ }^{57}$ Fernández 1973-1975, p. 13.

${ }^{58}$ AMB, LL.AA., 1445-1446-1477, f. 46r.
} 
rey. Una iniciativa que fue apoyada y que se impuso a pesar de la oposición de la institución monárquica, y no sólo en esta convocatoria sino a lo largo de todo el siglo $\mathrm{XV}^{59}$. Este ejemplo nos sirve para apuntar una primera delimitación de la región política de la ciudad de Burgos, es decir, aquella sobre la que la capital regional del Arlanzón despliega su influencia y ejerce un cierto liderazgo: la Submeseta Norte.

Sin embargo, esta preeminencia política no sólo se manifestó en las Cortes sino que se tradujo también en una encendida defensa del realengo frente a la nobleza en este ámbito geopolítico. Por eso, Burgos apoyó y defendió la condición de realengo de Navarrete $(1388)^{60}$, de Carrión de los Condes $(1465)^{61}$ y de los sesmos segovianos de Valdemoro y Casarrubios (1480). El 1 de julio del año señalado se presentó en el regimiento un hombre del linaje de Ferrand García, de la muy noble e leal çibdad de Segovia, y entregó una carta del concejo de Segovia en la que se hacía

saber a esta çibdad en conmo el Rey e Reyna nuestros sennores an fecho donaçión al mayordomo Cabrera e a la sennora donna Beatris de Belasco, su muger, de todo el sesmo de Baldemoro e de la mayor parte del sesmo de Casaruuyos que está cerca de la dicha çibdad de Segouia. E que por que esta çibdad de Burgos hera Cabeça de Castilla, que en onrra a ella por que esto ouiese por muy molesto o que sy se enviar sus mensajeros a los dichos sennores Rey e Reyna, nuestros sennores, a suplicar aquellos manden sus altezas remediar e que dieran revocar la dicha donación, pues sus altezas tienen jurado a estos reynos non enajenar cosa algunna de la Corona Real en lo qual esta çibdad de Burgos echará grand cargo para fazerlo guardar e a la dicha çibdad de Segouia. E que lo pedía e requerían de parte la Corona Real segund que esto e otras cosas más largamente en la dicha carta se contiene ${ }^{62}$.

Sin duda alguna, el documento es realmente notorio, pues manifiesta que Burgos no sólo intercedía por los elementos menos "ilustres" del sistema, sino también por las principales capitales regionales de Castilla. Como bien reza el documento, la ciudad del Eresma solicita la ayuda de la urbe del Arlanzón por que esta çibdad de Burgos hera Cabeça de Castilla. Cumpliendo su rol, la élite de gobierno burgalesa aceptó la petición, es decir, asumió su papel como uno de los representantes políticos más destacado del sistema de asentamientos de Castilla ${ }^{63}$. Sin embargo, hay que decir que su apoyo no tuvo

\footnotetext{
${ }^{59}$ Guerrero, Sánchez 1990; Carretero 1998.

${ }^{60}$ AMB, LL.AA., 1388, f. 96r. .

${ }^{61}$ AMB, LL.AA., 1465, f. 50v.

${ }^{62}$ AMB, LL.AA., 1480, f. 60v.

${ }^{63}$ AMB, LL.AA., 1480, f. 61r.
} 
efecto alguno, pues los sesmos de Valdemoro y Casarrubios siguieron estando en manos del señor de Moya durante todo el periodo estudiado ${ }^{64}$.

En segundo lugar, y con ello abordamos la escala eminentemente regional, la defensa del realengo como ideología subyace también al movimiento de formación de Hermandades, liderado por ciertas ciudades y que precede a la Hermandad de los Reyes Católicos ${ }^{65}$. A lo largo del siglo XV, Burgos convocó y participó en las siguientes Hermandades: 1421, 1432, 1441, 1450, 1456, 1466,1473 y 1476 , todas ellas como se aprecia por las fechas en momentos claves políticamente hablando de los reinados de Juan II, Enrique IV e Isabel I. Su análisis nos permite desentrañar aspectos importantes de la delimitación de la región política de la ciudad y del ejercicio de su centralidad. El primer hecho que hemos de resaltar es que las capitales regionales del reino eran las únicas entidades con capacidad para movilizar a una gran cantidad de asentamientos. En todas las hermandades burgalesas se pueden distinguir dos grandes áreas: la primera formada por las localidades más cercanas a la urbe. Aquellas que formaban parte de la Merindad y de la región cerealera anteriormente delimitada. La segunda formada por otros núcleos muy estrechamente vinculados con la ciudad pero alejados del epicentro. Por poner un ejemplo paradigmático, Burgos en la hermandad de 1450 envió mensajeros, en un primer momento, a Mahamud, la merindad de Campos, Presencio, Villahoz y Palenzuela ${ }^{66}$. El 21 de octubre, el concejo recibe las contestaciones, uniéndose a esta convocatoria también Castrojeriz y Balbases ${ }^{67}$. Finalmente, el 8 de diciembre acuden a la ciudad los representantes de Castrojeriz, Presencio, Balbases y Villahoz para confirmar las ordenanzas y los términos en los que se iba a constituir la coalición propuesta por el lugar central ${ }^{68}$. El mismo día, tras concretar las ordenanzas, la ciudad envía sus misivas a Lerma, Roa, Aranda, Palencia, Valladolid, Dueñas, Torquemada y a otros lugares para informarles de la constitución del cuerpo político-militar ${ }^{69}$. Una vez formada la Hermandad, era la ciudad del Arlanzón la que dirigía la institución, mientras que el resto de miembros que participaban seguían las órdenes y estrategias propuestas por el regimiento burgalés. Así, en la carta que Belorado envía a la ciudad el día 4 de julio de 1421 se afirma que somos prestos de nos juntar con vos a faser la dicha hermandad según el dicho señor rey manda e en la manera que vosotros fuere acordado ${ }^{70}$.

\footnotetext{
${ }^{64}$ Asenjo 1986, pp. 119-127.

${ }^{65}$ Álvarez 1974; Suárez 1951.

${ }^{66}$ AMB, LL.AA., 1450, f. 99v.

${ }^{67}$ AMB, LL.AA., 1450, ff. 102v y 103r.

${ }^{68}$ AMB, LL.AA., 1450, ff. 108v y 109r.

${ }^{69}$ AMB, LL.AA., 1450, f. 109r.

${ }^{70}$ AMB, LL.AA., 1450. f. 105v.
} 
Esta preeminencia de la ciudad en la hermandad, entre otras cosas, es la que explica el rechazo y reticencia con que la élite de gobierno burgalesa acogió el proyecto de Hermandad General del reino protagonizado por los Reyes Católicos y su tardanza en incorporarse finalmente al mismo ${ }^{71}$.

Cuando estaban constituidas y estructuradas, las hermandades burgalesas persiguieron directa e indirectamente los siguientes fines: en primer lugar, la defensa de las áreas económicas, sobre todo de la "región-granero", del bandidaje y de los abusos generados en las épocas de mayor inestabilidad, lo que demuestra la imbricación existente no sólo entre las regiones económicas, sino también entre dichas regiones y la región política burgalesa; en segundo lugar, la construcción de un frente común armado contra el bando opuesto al de la ciudad y, por lo tanto, la defensa de los principios ideológicos de la élite de gobierno; y, finalmente, la defensa del orden en el reino, de la superioridad del realengo, sobre todo en el reinado de Juan II, ya que la ciudad siempre se mantuvo leal a la Corona y a las decisiones tomadas por el rey. En definitiva, las hermandades burgalesas tenían objetivos económicos, políticos e ideológicos. Estos últimos no han sido puestos de relieve muy a menudo en las investigaciones. Está claro que cuando el reino se dividía en dos las actividades delictivas se multiplicaban exponencialmente. Sin embargo, analizando los casos que se producen en las inmediaciones de la ciudad de Burgos, se puede determinar que la mayoría de los malhechores perseguidos por las hermandades eran producto de las luchas políticas, es decir, eran agentes al servicio de los partidos, en los cuales participaba la urbe como sujeto activo. Por lo tanto, aplicando la lógica, los cuerpos armados burgaleses perseguirían con más ahínco a los hombres que actuaban en contra de los intereses del bando que apoyaba la élite de gobierno. Así se entiende que en julio de 1466 Burgos formase parte de una hermandad de ciudades que tenía como objetivo principal defender la postura del príncipe Alfonso ${ }^{72}$. Por eso, en una de las crónicas dedicadas a Enrique IV se señala que: E como entonçe çerca de Burgos la Hermandat mucho se esforçase, con dura mano castigaron mucho de los que syguían al rey don Enrrique, entre los quales mataron un famosso ladrón llamado Persseval, que tenía ocupada la torre de Villassandino ${ }^{73}$. O que el 2 de abril de 1476, el obispo, con muy buenas palabras, comunicase a la ciudad que le placía ayudar en la formación de la hermandad, salvo si el rey de Portugal, al cual apoyaba, mandaba hacer la guerra a los partidarios de Isabel I, ya que en ese

\footnotetext{
${ }^{71}$ Guerrero $1986 b$.

${ }^{72}$ ACB, REG, Leg. 17, f. 403.

${ }^{73}$ Crónica anónima de Enrique IV de Castilla 1454-1474 (Crónica castellana), ed. Sánchez, p. 192.
} 
caso él non podrá ayudar a la dicha çibdad por el seguir su partido, e porque él non acogerá a los que la tal guerra fisiesen en su casa ny menos los fauoesçería ${ }^{74}$. Por consiguiente, las hermandades no sólo eran coaliciones concejiles creadas para restablecer el orden público, sino que eran auténticas ligas políticas dirigidas por las principales ciudades del Reino para perseguir y eliminar a sus rivales.

\section{CONCLUSIONES}

Creemos poder afirmar, a la luz de todo lo visto que la perspectiva regional dota al análisis de la ciudad bajomedieval de novedosos e inéditos puntos de vista que proporcionan modelos de análisis capaces de cuestionar paradigmas tradicionalmente aceptados por la historiografía, al tiempo que permite trascender los antiguos conceptos de espacio urbano vinculados bien al ámbito jurisdiccional de la ciudad, bien a la comarca circundante.

En Burgos, una simple muestra como la que aquí plasmamos permite confirmar la existencia de amplias regiones económicas y políticas, diferentes en función de la distinta lógica que se haya en su origen, pero todas ellas imbricadas y dependientes entre sí por la dinámica interna del sistema al que pertenecen: región cerealera y región vinícola, regiones productivas y regiones distributivas, regiones económicas y regiones políticas. Ello permite afirmar que Burgos funcionaba en la Baja Edad Media como una gran capital regional.

Para concluir nos gustaría destacar un hecho absolutamente transversal a todo lo afirmado en este estudio e implícito en todo lo dicho: el papel de las élites burgalesas en la génesis, potenciación y mantenimiento de la capitalidad y centralidad regional de Burgos, así como de su status privilegiado en el sistema-reino castellano. Los intereses geoeconómicos, productivos y financieros de los patricios de Burgos condicionan la creación, defensa y administración de las diferentes regiones económicas de Burgos, de la misma forma que su influencia, capacidad financiera, prestigio político y redes clientelares configuran la retícula que sostiene la jerarquía y liderazgo político que fue capaz de ejercer la ciudad del Arlanzón en la centuria del cuatrocientos.

${ }^{74}$ AMB, LL.AA., 1476, f. $11 \mathrm{v}$. 


\section{BIBLIOGRAFÍA CITADA}

Álvarez Borge, Ignacio (1987), El feudalismo castellano y el Libro Becerro de las Behetrías. La Merindad de Burgos, León, Universidad de León.

Álvarez Biezo, Sabina; Carreras Zalama, Agustín (1998), Valladolid en época de los Reyes Católicos según el alarde de 1503, Valladolid, Universidad de Valladolid.

Álvarez de Morales, Antonio (1974), Las Hermandades, expresión del movimiento comunitario en España, Valladolid, Departamento de Historia Medieval.

Arízaga Bulumburu, Beatriz (1985), El abastecimiento de las villas vizcaínas medievales: política comercial de las villas respecto al entorno y a su interior, "En la España medieval" 6, pp. 293-316.

Arregui Zamorano, Pilar (2000), Monarquía y señorío en la Castilla moderna. Los adelantamientos de Castilla, León y Campos, Valladolid, Junta de Castilla y León.

Asenjo González, María (1986), Segovia: la ciudad y su tierra a fines del Medievo, Segovia, Diputación Provincial de Segovia.

Asenjo González, María (2005), Las ciudades medievales castellanas. Balance y perspectivas de su desarrollo historiográfico (1990-2004), "En la España medieval" 28, pp. 415-453.

Beaujeu-Garnier, Jacqueline; Chabot, Georges (1970), Tratado de Geografía Urbana, Barcelona, Vicens Vives.

Benito, Félix de (2000), La formación de la ciudad medieval: la red urbana en Castilla y León, Valladolid, Universidad de Valladolid.

Bertalanffy Ludwig von (1978), Tendencias en la teoría general de sistemas, Madrid, Alianza Editorial.

Bonachía Hernando, Juan Antonio (1978), El Concejo de Burgos en la Baja Edad Media (1345-1426), Valladolid, Universidad de Valladolid.

Bonachía Hernando, Juan Antonio (1984), La artesanía; las actividades comerciales; otras actividades, en Valdeón Baruque, Julio (dir.), Burgos en la Edad Media, Valladolid, Junta de Castilla y León, pp. 274-355.

Bonachía Hernando, Juan Antonio (1988), El señorío de Burgos durante la Baja Edad Media (1255-1508), Valladolid, Universidad de Valladolid.

Bonachía Hernando, Juan Antonio (1992), Abastecimiento urbano, mercado local y control municipal: la provisión y comercialización de la carne en Burgos (siglo XV), "Espacio, tiempo y forma. Serie III. Historia medieval" 5, pp. 85-162. 
Bonachía Hernando, Juan Antonio (1996), "Mas honrada que ciudad de mis reinos...": La nobleza y el honor en el imaginario urbano (Burgos en la Bajad Edad Media), en Bonachía Hernando, Juan Antonio (coord.), La ciudad medieval: aspectos de la vida urbana en la Castilla bajomedieval, Valladolid, Universidad de Valladolid, pp. 169-212.

Buchholzer-Rémy, Laurence (2006), Une ville en ses réseaux. Nuremberg à la fin du moye age, París, Belin.

Capel, Horacio (2003), Una mirada histórica sobre los estudios de redes, "Geotrópico" 1/1, pp. 30-65.

Carrasco Manchado, Ana Isabel (2009), Desplazamientos e intentos de estabilización: la corte de los Trastámara, "E-Spania: Revue électronique d'études hispaniques médiévales", 8.

Carretero Zamora, Juan Manuel (1998), Cortes, monarquía y ciudades. Las Cortes de Castilla a comienzos de la época moderna (1476-1515), Madrid, Siglo XXI.

Carter, Harold (1974), El estudio de la Geografía urbana, Madrid, Instituto de Estudios de Administración Local.

Casado Alonso, Hilario (1980), La propiedad eclesiástica en la ciudad de Burgos en el siglo XV: el cabildo catedralicio, Valladolid, Universidad de Valladolid.

Casado Alonso, Hilario (1987), Señores, mercaderes y campesinos: la comarca de Burgos a fines de la Edad Media, Valladolid, Junta de Castilla y León.

Casado Alonso, Hilario (1997), Crecimiento económico y redes de comercio interno en la Castilla septentrional (siglos XV y XVI), en Fortea Pérez, José Ignacio (ed.), Imágenes de la diversidad. El mundo urbano en la Corona de Castilla ( $s$. XVI-XVIII), Santander, Universidad de Cantabria, pp. 283-322.

Casado Alonso, Hilario (2001), El comercio burgalés y la estructuración del espacio económico español a fines de la Edad Media, en Itinerarios medievales e identidad hispánica: XXVII Semana de Estudios Medievales, Estella 17 a 21 de julio de 2000, Pamplona, Gobierno de Navarra, pp. 329-356.

Collantes de Terán Sánchez, Antonio (2004), Las ciudades andaluzas en la transición de la Edad Media a la Moderna, "Boletín de la Real Academia Sevillana de Buenas Letras: Minervae Baeticae" 32, pp. 31-124.

Collantes de Terán Sánchez, Antonio (2009-2010), La Andalucía de las ciudades, "Anales de la Universidad de Alicante. Historia medieval" 16, pp. 111-132. 
Collantes de Terán Sánchez, Antonio (2014), Sevilla en el sistema urbano de la Andalucía bajomedieval, "Edad Media: revista de Historia" 15, pp. 79-96.

Crónica anónima de Enrique IV de Castilla 1454-1474 (Crónica castellana) ed. crítica y comentada de María Pilar Sánchez-Parra, 2. vols., Madrid, Ediciones de la Torre, 1991.

Díaz de Durana Ortiz de Urbina, José Ramón (1990), La recuperación del siglo XV en el nordeste de la Corona de Castilla, "Studia historica. Historia medieval" 8, pp. 79-115.

Dickinson, Robert E. (1961), Ciudad, Región y Regionalismo: contribución geográfica a la ecología humana, Barcelona, Omega.

Dutour, Thierry (2004), La ciudad medieval. Orígenes y triunfo de la Europa urbana. Barcelona, Paidós Ibérica.

Fernández de Palencia, Alonso (1973-1975), Crónica de Enrique IV, Madrid, Atlas.

Ferrer Regales, Manuel (1992), Sistemas urbanos. Los países industrializados del hemisferio norte e Iberoamérica, Madrid, Síntesis.

Galloway, John A (2000), Trade, Urban Hinterlands and Market integration, c. 1300-1600, Londres, Centre for Metropolitan History, Institute of Historical Research, 2000.

George, Pierre (1982), Geografía Urbana, Barcelona, Ariel.

Goicolea Julián, Francisco Javier (1994), La política económica del concejo de Haro a finales de la Edad Media: la comercialización del vino, "Espacio, tiempo y forma. Serie III. Historia medieval" 7, pp. 103-120.

Goicolea Julián, Francisco Javier (1999), Haro: una villa riojana del linaje Velasco a fines del Medievo, Logroño, Instituto de Estudios Riojanos.

Goicolea Julián, Francisco Javier (2007), El vino en el mundo urbano riojano a finales de la Edad Media, "En la España medieval" 30, pp. $217-$ 244.

González Arce, José Damián (2009), Gremios y cofradías en los reinos medievales de León y Castilla. Siglos XII-XV, Palencia, Región Editorial.

Guerrero Navarrete, Yolanda (1986a), Organización y gobierno en Burgos durante el reinado de Enrique IV de Castilla, 1453-1476, Madrid, Universidad Autónoma de Madrid.

Guerrero Navarrete, Yolanda (1986b), La Hermandad de 1476 y Burgos: Un factor decisivo en la transformación del poder municipal a fines de la Edad Media, "Anuario de estudios medievales" 16, pp. 533-556.

Guerrero Navarrete, Yolanda (1989), Aproximación a las relaciones campociudad en la Edad Media: el alfoz y el señorío burgalés, génesis y 
primer desarrollo, "Historia. Instituciones. Documentos. Serie III. Historia medieval" 16, pp. 15-46.

Guerrero Navarrete, Yolanda (2000-2002), Orden público y corregidor en Burgos (siglo XV), "Anales de la Universidad de Alicante. Historia medieval" 13, pp. 59-102.

Guerrero Navarrete, Yolanda (2009-2010), Poder patricio e identidad política en Burgos, "Anales de la Universidad de Alicante. Historia medieval" 16, pp. 63-91.

Guerrero Navarrete, Yolanda; Sánchez Benito, José María (1990), La Corona y el poder municipal. Aproximación a su estudio a través de la elección a procuradores en Cortes en Cuenca y Burgos en el siglo $X V$, en Las Cortes de Castilla y León 1188-1988, actas de la Tercera Etapa del Congreso Científico sobre la Historia de las Cortes de Castilla y León: León, del 26 al 30 de Septiembre de 1988, Valladolid, Cortes de Castilla y León, vol. 1, pp. 381-399.

Huezt de Lepms, Alain (2004), Vinos y viñedos de Castilla y León, Valladolid, Junta de Castilla y León.

Iradiel Murugarren, Paulino (1974), Evolución de la industria textil castellana en los siglos XIII-XVI. Factores de desarrollo, organización y costes de la producción manufacturera en Cuenca, Salamanca, Universidad de Salamanca.

Iradiel Murugarren, Paulino (2003), Metrópolis y hombres de negocios, en Ruiz de la Peña, José Ignacio (ed.), Las sociedades urbanas en la España Medieval. XXIX Semana de Estudios Medievales, Estella, 15 a 19 de julio de 2002, Pamplona, Gobierno de Navarra, pp. 277-310.

Johnson, James H. (1987), Geografía Urbana, Barcelona, Oikos-Tau.

Ladero Quesada, Manuel F. (1995), Sobre el viñedo y el vino en Zamora y su tierra a finales de la Edad Media, "Studia Zamorensia" 2, pp. 27-47.

Ladero Quesada, Miguel Ángel (1987), El sistema político en la monarquía castellana de los Reyes Católicos: Corona, Nobleza y Ciudades, en Hernán Cortés y su tiempo: actas del Congreso "Hernán Cortes y su tiempo", V Centenario (1485-1985), Cáceres, Editora Regional de Extremadura, vol. 2, pp. 500-519.

Mansilla Reoyo, Demetrio (1985), Obispado y Monasterios, en Montenegro Duque, Ángel; Palomares Ibáñez, Jesús María (coords.), Historia de Burgos II. Edad Media, Burgos, Caja de Ahorros de Burgos, pp. 295-356.

Martín Cea, Juan Carlos (1992), El mundo rural castellano a fines de la Edad Media. El ejemplo de Paredes de Nava en el siglo XV, Valladolid, Universidad de Valladolid. 
Martín Galán, Manuel (1981), Fuentes y métodos para el estudio de la demografía histórica castellana durante la Edad Moderna, "Hispania" 41/148, pp. 231-326.

Martínez Sopena, Pascual (1985), Tierra de Campos occidental. Poblamiento, poder y comunidad del siglo X al XII, Valladolid, Institución Cultural Simancas.

Molénat, Jean Pierre (1971), Chemins et ponts du nord de la Castille au temps des Rois Catholiques, "Mélanges de la Casa de Velázquez" 7, pp. 115-162.

Monsalvo Antón, José María (1986), Poder político y aparatos de estado en la Castilla bajomedieval: Consideraciones sobre su problemática, "Studia historica. Historia Medieval" 4, pp. 101-169.

Monsalvo Antón, José María (2000-2002), Centralización monárquica castellana y territorios concejiles (algunas hipótesis a partir de las ciudades medievales de la región Castellano-Leonesa), "Anales de la Universidad de Alicante. Historia medieval" 13, pp. 1-116.

Montero Málaga, Alicia Inés (2012), El linaje de los Velasco y la ciudad de Burgos (1379-1474). Identidad y poder político, Madrid, Ergástula.

Pascual Gete, Hilarión (1986), Medina y su tierra durante los siglos XV y XVI: Una economía agraria en el apogeo comercial de sus viñedos de calidad, en Lorenzo Sanz, Eufemio (coord.), Historia de Medina del Campo y su tierra. Nacimiento y expansión, Valladolid, Ayuntamiento de Medina del Campo, vol. 1, pp. 233-314.

Pérez-Bustamante González de la Vega, Rogelio (1981), El marco jurídico para la construcción y reparación de caminos. Castilla, siglos XIV y XV, en Les Communications dans la Péninsule Ibérique au MoyenÂge, París, Centre National de la Recherche Scientifique, pp. 163-178.

Precedo Ledo, Andrés (1998), La red urbana, Madrid, Síntesis.

Pulgar, Fernando del (2008), Crónica de los Reyes Católicos, 2. vols., Barcelona, Marcial Pons.

Ruiz Martín, Felipe (1967), La población española al comienzo de los tiempos modernos, "Cuadernos de Historia" 1, pp. 189-202.

Sebastián Moreno, Javier (2017), La ciudad medieval como capital regional. Burgos en el siglo XV, Madrid, UAM Ediciones.

Serrano, Luciano (1935), El Obispado de Burgos y Castilla primitiva: desde el siglo V al XIII, Madrid, Instituto de Valencia de Don Juan.

Solórzano Telechea, Jesús Ángel (2002), Santander en la Edad Media, Santander, Universidad de Cantabria.

Suárez Fernández, Luis (1951), Evolución histórica de las Hermandades castellanas, "Cuadernos de Historia de España” 16, pp. 6-68. 
Vela Santamaría, Francisco Javier (1997), El sistema urbano del norte de Castilla en la segunda mitad del siglo XVI, en Ribot García, Luis Antonio; Rosa, Luigi, Ciudad y mundo urbano en la Época Moderna, Valladolid, Actas, pp. 15-44.

Villuga, P. Juan (1951), Repertorio de todos los caminos de España, Madrid, Real Academia de la Historia.

Fecha de recepción del artículo: octubre 2017

Fecha de aceptación y versión final: marzo 2018 